\title{
TRAINING RETURN-ON-INVESTMENT: SUATU PERSPEKTIF DALAM MENGEVALUASI KEEFEKTIFAN PROGRAM PELATIHAN
}

\author{
Oki Sunardi \\ Dosen Universitas Bunda Mulia, Jakarta \\ Email: osunardi@yahoo.com
}

\begin{abstract}
Every year new challenges emerge in the field of training and development, for example, competency development, outsourcing, e-learning, and knowledge management. The purpose of this study is to conceptualize the different dimensions of access to employee development. The concept of Kirkpatrick's Four-Level Framework can be used to choose which levels are appropriate in evaluating a training program. Lilly's Four Steps of Computing ROI training can also be adapted to the ROI calculation process. The main issue, in the pursuit of profitability and competitive advantage, top management is looking at all functions for a return-on-investment. The main question is, "is it really the training program itself that affects the employee performance?" This research uses 'time series with comparison group' technique as a tool to isolate the effects of training. Once the isolation is completed, the ROI calculation can be analyzed then.
\end{abstract}

Keywords: Effectiveness of training; isolating the effects of training; time series with comparison group; $R O I$ calculation

Pendahuluan

Setiap tahun selalu diwarnai dengan munculnya tantangan - tantangan baru di bidang pelatihan dan pengembangan (training and development). Pertanyaan-pertanyaan yang sama hampir selalu timbul setiap kali seorang manajer mengajukan suatu proposal program pelatihan. Bagaimana komentar para karyawan terhadap program pelatihan yang sebelumnya pernah diadakan oleh organisasi (perusahaan)? Apakah terdapat perubahan mental positif dan peningkatan kinerja setelah karyawan mengikuti program pelatihan? Bagaimana kontribusi program pelatihan tersebut terhadap kinerja (keuangan) perusahaan? Jawaban positif atas pertanyaan- pertanyaan ini akan menentukan lolos tidaknya suatu proposal.

American Management Association (AMA) pada tahun 1995 melaporkan bahwa terdapat korelasi positif antara peningkatan anggaran pelatihan dengan peningkatan profit organisasi. Pada tahun yang sama, New York Times melaporkan bahwa berdasarkan survei yang dilakukan Biro Sensus Amerika Serikat bersama University of Pennsylvania terhadap 3,000 organisasi bisnis, diperoleh kesimpulan bahwa $10 \%$ peningkatan edukasi karyawan berimbas pada $8.6 \%$ peningkatan produktivitas karyawan. Sebagai perbandingan, peningkatan sebesar $10 \%$ dalam investasi modal kapital (peralatan, bangunan, dan mesin) hanya menghasilkan pertambahan produktivitas kerja karyawan sebesar 3.4\% (Gordon, 2002). Kondisi ini tentunya dapat mempertegas pengaruh positif yang dapat dihasilkan oleh suatu program pelatihan.

\section{Evaluasi Pelatihan: Konsep Dasar}

Pelatihan dapat didefinisikan sebagai suatu upaya sistematis untuk meningkatkan pengetahuan (knowledge), ketrampilan (skills), dan sikap kerja (behaviors) para karyawan melalui proses belajar. Tujuan pelatihan adalah untuk meningkatkan knowledge, skills, atau behaviors, agar para karyawan dapat lebih optimal dalam menjalankan fungsi dan tugas jabatannya sehari-hari (Noe, 2002).

Goldstein (1993) mendefinisikan evaluasi pelatihan sebagai suatu proses pengumpulan informasi secara sistematis, baik informasi yang sifatnya deskriptif maupun judgemental, yang diharapkan dapat membantu dalam mengambil keputusan secara efektif, dalam hal pemilihan, adopsi, maupun modifikasi terhadap berbagai kegiatan operasional dalam organisasi.

Noe (2002) mengartikan evaluasi pelatihan sebagai suatu proses pengumpulan keluaran yang dibutuhkan untuk menilai apakah sebuah program pelatihan sudah efektif atau belum.

Kirkpatrick \& Kirkpatrick (2006) menjelaskan bahwa prosedur evaluasi pelatihan dapat dibedakan menjadi empat tingkat kriteria, yang disebutnya sebagai four-level framework, yaitu reaksi (reaction), pembelajaran (learning), perilaku (behavior), dan hasil (results). Reaksi, didefinisikan sebagai bagaimana tanggapan peserta terhadap program pelatihan. Pembelajaran, merupakan tahapan di mana peserta diuji 
secara tertulis untuk mengetahui sejauh mana materi pelatihan telah diterima oleh mereka. Perilaku, ditujukan untuk mengukur perubahan sikap kerja dalam kegiatan sehari-hari. Hasil digunakan untuk mengetahui seberapa besar program pelatihan berpengaruh terhadap kinerja perusahaan.

Tabel 1. Empat Tingkatan Kriteria Evaluasi Pelatihan

\begin{tabular}{cll}
\hline Tingkat & Kriteria Evaluasi & \multicolumn{1}{c}{ Fokus } \\
\hline \hline 1 & Reaksi & Kepuasan para peserta pelatihan \\
2 & Pembelajaran & Pemahaman akan pengetahuan, ketrampilan, perilaku, dan sikap kerja \\
3 & Perilaku & Perubahan perilaku dan sikap dalam kerja \\
4 & Hasil & Hasil yang dicapai (kuantitatif) \\
\hline
\end{tabular}

Sumber: Dirangkum dari Kirkpatrick \& Kirkpatrick (2006)

Baik praktisi bidang pelatihan maupun para akademisi berpendapat bahwa kriteria evaluasi yang lebih komprehensif sangat dibutuhkan, yaitu yang dapat menggambarkan tingkat pengembalian moneter program pelatihan itu sendiri (Noe, 2002). Noe, 2002; Lilly, 2001; Fitz-enz, 2000; Phillips, 1997, menjelaskan bahwa evaluasi pelatihan dengan kriteria ROI merupakan teknik evaluasi yang paling objektif dibanding empat kriteria lainnya, mengingat unsur kuantitatif merupakan hal yang dominan pada metode ini. Secara sistematis, tingkatan evaluasi pelatihan dapat dilihat pada Tabel 2.

Tabel 2. Tingkatan Evaluasi Pelatihan

\begin{tabular}{|c|c|c|c|}
\hline Tingkatan Evaluasi & Tujuan Pengukuran & Alat dan Cara & Keterangan \\
\hline $\begin{array}{l}\text { 1. Reaction (and } \\
\text { planned action) }\end{array}$ & $\begin{array}{l}\text { Participant's reaction and } \\
\text { satisfaction to the content } \\
\text { and delivery of pelatihan. }\end{array}$ & $\begin{array}{l}\text { Participant's complete } \\
\text { evaluation forms and/or } \\
\text { develop action plans for } \\
\text { implementing new knowledge. }\end{array}$ & $\begin{array}{l}\text { Subjective but has } \\
\text { some usefulness. } \\
\text { If follow-up is } \\
\text { scheduled, participant's } \\
\text { action plans will be } \\
\text { more realistic. }\end{array}$ \\
\hline 2. Learning & $\begin{array}{l}\text { Skills, knowledge or attitude } \\
\text { changes as a result of } \\
\text { pelatihan program. }\end{array}$ & $\begin{array}{l}\text { Tests via paper and pencil or } \\
\text { computerized format. }\end{array}$ & $\begin{array}{l}\text { Tests must be } \\
\text { assessed for validity } \\
\text { and reliability. }\end{array}$ \\
\hline 3. Behavior & $\begin{array}{l}\text { Changes in behavior on the } \\
\text { job as a result of pelatihan. }\end{array}$ & $\begin{array}{l}\text { Performance reviews and } \\
\text { observations. }\end{array}$ & $\begin{array}{l}\text { Assumption is that if the } \\
\text { skills are applied, } \\
\text { results will follow. }\end{array}$ \\
\hline 4. Results & $\begin{array}{l}\text { Impact of pelatihan on } \\
\text { business activities and } \\
\text { processes. }\end{array}$ & $\begin{array}{l}\text { Cost reduction, productivity } \\
\text { increases, improved quality, } \\
\text { reduced labor hours, } \\
\text { decreased production / } \\
\text { processing time, etc. }\end{array}$ & $\begin{array}{l}\text { Critical tasks are } \\
\text { isolating the effects of } \\
\text { pelatihan and capturing } \\
\text { appropriate data. }\end{array}$ \\
\hline $\begin{array}{l}\text { 5. Return on } \\
\text { Investment (ROI) }\end{array}$ & $\begin{array}{l}\text { Compares the costs of the } \\
\text { pelatihan program with } \\
\text { monetary results and is } \\
\text { usually expressed as a } \\
\text { percentage. }\end{array}$ & $\begin{array}{l}\text { Detailed, comprehensive data } \\
\text { collection and analysis of } \\
\text { costs \& benefits. Accounting } \\
\text { expertise helpful. Time value } \\
\text { of money is a factor. }\end{array}$ & $\begin{array}{l}\text { The most } \\
\text { comprehensive and } \\
\text { objective evaluation } \\
\text { technique, but the } \\
\text { process can be very } \\
\text { costly and time } \\
\text { consuming. }\end{array}$ \\
\hline
\end{tabular}

Sumber: Lilly (2001), halaman 2 


\section{ROI Program Pelatihan}

ROI adalah suatu ukuran dalam bentuk keuntungan moneter yang diperoleh oleh suatu organisasi setelah jangka waktu tertentu sebagai timbal balik terhadap investasi suatu program pelatihan. ROI dihitung berdasarkan estimasi atau data terhadap biaya maupun keuntungan yang berhubungan dengan program pelatihan. Dengan memanfaatkan ROI ini, unit bisnis dapat secara efektif mengalokasikan sumber daya yang ada untuk meningkatkan kinerja dan mendorong keberhasilan suatu organisasi (Carr, 1999).

Lilly (2001) menjelaskan empat langkah mengukur ROI pelatihan, yaitu: (1) mengisolasi pengaruh pelatihan terhadap hal-hal diluar pelatihan, (2) mengkonversi pengaruh-pengaruh pelatihan ke dalam bentuk moneter, (3) menghitung biaya pelatihan, dan (4) membandingkan biaya pelatihan dengan nilai tambah moneter yang diperoleh sebagai hasil pelatihan.

Gambar 1. Model ROI

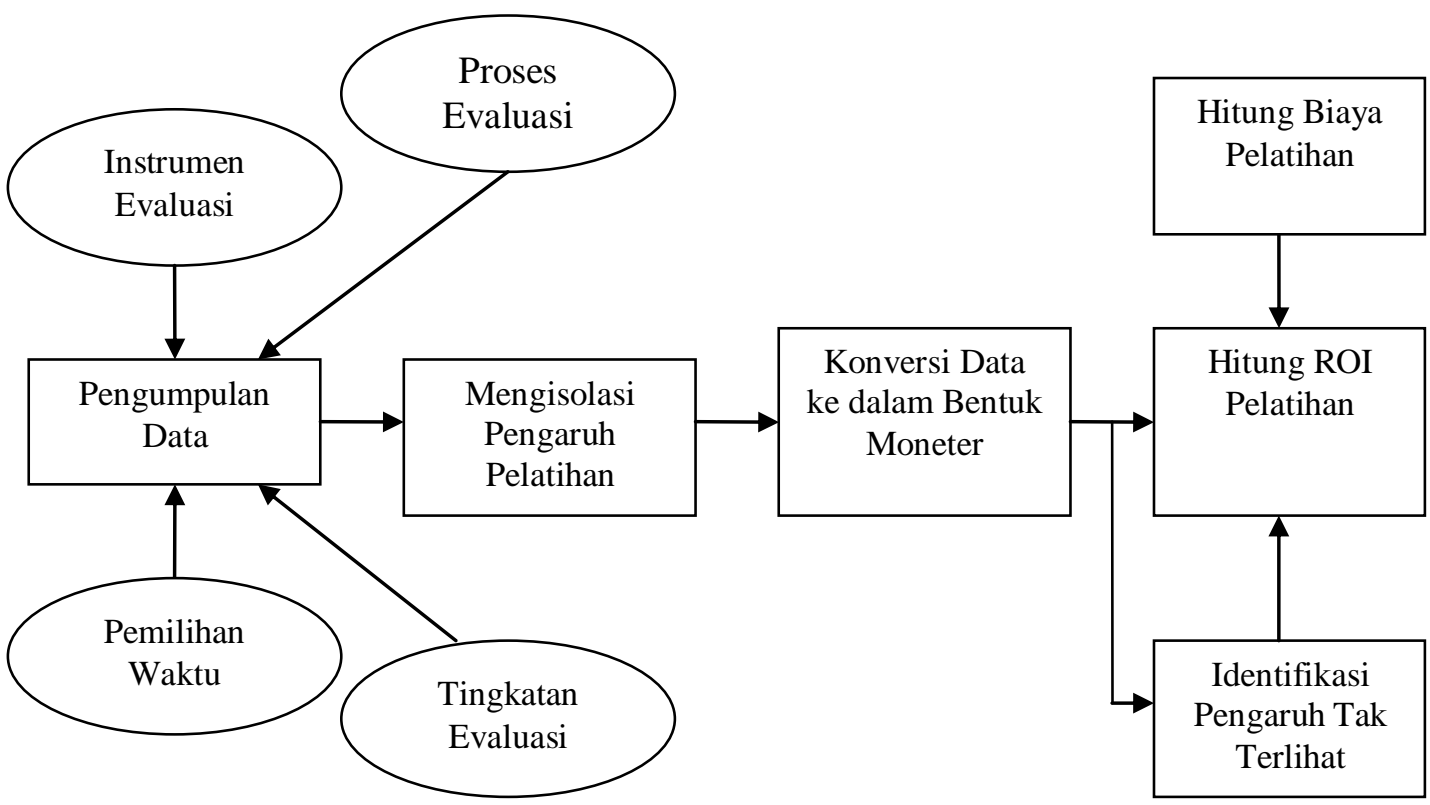

Sumber: Phillips (1997), halaman 25

\section{Mengisolasi Pengaruh Pelatihan}

Proses pertama dalam perhitungan ROI ini merupakan tahap untuk meminimasi ancaman terhadap validitas evaluasi pelatihan (threats to validity), baik validitas internal maupun validitas eksternal. Ancaman-ancaman ini bersifat variabel, yang berasal dari luar program pelatihan, yang dapat mempengaruhi hasil yang ingin dicapai dari pelatihan (Goldstein, 1993). Noe (2002) menjelaskan ancaman-ancaman terhadap validitas evaluasi pelatihan seperti pada Tabel 3 .

Validitas eksternal didefinisikan sebagai kemampuan mengeneralisasi hasil penelitian terhadap lingkungan, individu, atau pun peristiwa, di luar tempat penelitian berlangsung. Validitas internal didefinisikan sebagai derajat kepercayaan (peneliti) terhadap pengaruh hubungan sebab akibat dalam suatu penelitian (Sekaran, 2003)

\section{Tabel 3. Ancaman terhadap Validitas}

\begin{tabular}{ll}
\hline Ancaman terhadap Validitas Internal & \multicolumn{1}{c}{ Deskripsi } \\
\hline Perusahaan & $\begin{array}{l}\text { Hal-hal yang pernah terjadi, mungkin muncul kembali dan } \\
\text { mempengaruhi hasil pelatihan. }\end{array}$ \\
$\begin{array}{l}\text { Sejarah } \\
\text { Karyawan }\end{array}$ & $\begin{array}{l}\text { Perubahan terhadap prestasi kerja mungkin disebabkan karena } \\
\text { Kematanganan fisik pesertanya, atau dengan tercapainya kestabilan } \\
\text { emosional pesertanya. }\end{array}$
\end{tabular}


Pengunduran diri

Perbedaan antar kelompok dalam perusahaan

\section{Ukuran Keberhasilan}

Ujian

Instrumentasi

Regresi

Ancaman terhadap Validitas Eksternal

Reaksi terhadap pre-test

Reaksi terhadap proses evaluasi

Interaksi antara pemilihan peserta dengan program pelatihan

Interaksi antar metode pelatihan
Peserta pelatihan mengundurkan diri.

Perbedaan kompetensi (pengetahuan, ketrampilan, kemampuan, dan sikap) antara kelompok yang mengikuti pelatihan dengan kelompok pembanding yang ikut mempengaruhi hasil pelatihan.

Peserta akan cenderung berusaha lebih baik ketika mengikuti tes sesudah pelatihan.

Intrepretasi peserta terhadap hasil pelatihan berubah sejalan dengan berlangsungnya evaluasi.

Peserta pelatihan dengan nilai tinggi dan rendah akan bergeser mendekati prestasi rata-rata pada saat penilaian.

\section{Deskripsi}

Penggunaan materi tes sebelum pelatihan akan menyebabkan peserta memberikan jawaban terbaik terhadap pertanyaan-pertanyaan dalam tes.

Peserta yang merasa sedang dievaluasi akan berusaha lebih keras selama pelatihan berlangsung.

Karakteristik peserta mempengaruhi keefektifan program pelatihan.

Hasil yang dicapai peserta yang mendapatkan metode pelatihan yang berbeda hanya dapat digeneralisasikan terhadap peserta lainnya yang mendapatkan metode pelatihan yang sama.

\section{Sumber: Dirangkum dari Noe (2002)}

Terdapat beberapa metode untuk mengontrol "ancaman" terhadap validitas. Goldstein, 1993; Lilly, 2001; Noe, 2002, menjelaskan bahwa untuk meningkatkan validitas internal pelatihan terlebih dahulu harus dapat mengukur perubahan-perubahan yang muncul sebagai dampak dari pelatihan itu sendiri. Konsekuensinya, peneliti harus tahu bagaimana tingkat kinerja sebelum (pretest) dan sesudah pelatihan dilakukan (posttest).

Goldstein, 1993; Lilly, 2001; Noe, 2002, juga menjelaskan alternatif kedua yang dapat dilakukan untuk mengetahui bila ada ancaman terhadap validitas evaluasi pelatihan, yaitu dengan menggunakan dua kelompok sampel. Kelompok pertama menerima pelatihan sementara kelompok kedua (control group) tidak. Produktivitas atau kinerja kedua kelompok diukur dan dibandingkan.

\section{Mengkonversi Pengaruh-pengaruh Pelatihan ke dalam Nilai Moneter}

Pengaruh atau nilai tambah yang diperoleh sebagai hasil dari program pelatihan harus selalu diidentifikasi, dipilah, dan dikonversikan ke dalam bentuk moneter. Perubahan terhadap kinerja karyawan sebaiknya dinilai dengan melibatkan berbagai pihak seperti supervisor, direktur, manajer, dan pihak lain dalam organisasi. Keputusan dengan melibatkan berbagai pihak akan jauh lebih objektif ketimbang menyerahkan semua penilaian kepada Manajer Sumber Daya Manusia.

Pengaruh dapat bersifat terlihat (tangible) atau tak terlihat (intangible), dan biasanya disebut sebagai "hard data" dan "soft data". Hard data bersifat kuantitatif, statistikal, berorientasi angka dan dengan mudah dapat dikonversikan ke dalam bentuk moneter. Soft data lebih bersifat kualitatif dan lebih sulit diukur dan dikonversikan ke dalam bentuk uang. Contoh soft data dapat berupa peningkatan kepuasan kerja, peningkatan komitmen organisasi, peningkatan komunikasi antar karyawan berbeda lini, dan sebagainya.

\section{Menghitung Biaya Pelatihan}

Tahap ini sering disebut sebagai analisis biaya-manfaat (cost-benefit analysis). Analisis biayamanfaat dalam perhitungan ROI adalah proses menentukan nilai ekonomis dari suatu program pelatihan dengan menggunakan metode akuntansi. Menentukan nilai ekonomis dari suatu program pelatihan meliputi 
perhitungan biaya pelatihan (cost) dan hasil (benefits ) yang didapat setelah mengikuti program pelatihan (Noe, 2002).

Dalam menghitung biaya suatu program pelatihan, jangan lupa untuk memperhitungkan biayabiaya tidak langsung, seperti penggunaan material, peralatan, ruangan, dan sebagainya. Contoh biaya yang terlibat dalam program pelatihan:

1) Pengembangan modul - perancangan, penulisan, ilustrasi, validasi tes dan instrumen evaluasi.

2) Gaji dan upah staf HRD, manajer, dan karyawan lain yang terlibat dalam perancangan program.

3) Gaji dan upah instruktur dan staf pendukungnya.

4) Gaji dan upah peserta pelatihan (sering disebut "seat time").

5) Upah karyawan tidak tetap yang dipekerjakan untuk menjaga tingkat produktivitas selama masa pelatihan.

6) Kehilangan pendapatan selama peserta terlibat dalam pelatihan.

7) Honor trainer dari luar organisasi atau konsultan.

8) Bahan pelatihan - cetakan, foto kopi, video, disket, alat tulis kantor yang diperoleh karena sengaja membeli dari suplier di luar organisasi.

9) Peralatan dan fasilitas - meliputi peralatan audio-video, komputer, software, biaya ruangan atau biaya sewa fasilitas lainnya.

10) Administrasi - marketing, penjadualan, pendaftaran, dokumentasi, foto kopi, telepon, dan waktu yang digunakan untuk tugas-tugas administratif.

11) Logistik - penginapan, makanan, dan pengiriman.

12) Waktu perjalanan - menuju dan kembali dari tempat pelatihan.

\section{Membandingkan Biaya Pelatihan dengan Nilai Tambah Moneter}

Rumus ROI adalah sebagai berikut:

$$
\mathrm{ROI}=\text { Net Program Benefits } \times 100 \%
$$

Total Incurred Costs

Net Program Benefits adalah program benefits dikurangi total incurred costs. Program benefits merupakan sejumlah keuntungan yang diperoleh karena melakukan investasi. Total incurred costs merupakan biaya yang dikeluarkan sebagai investasi. Rumus ROI ini diturunkan dari rumus BCR (Benefits/Cost Ratio).

$$
\mathrm{BCR}=\frac{\text { Program Benefits }}{\text { Program Costs }}
$$

Nilai ROI yang didapat ini kemudian dianalisis dan dimanfaatkan sebagai salah satu hal penting dalam pengambilan keputusan maupun perbaikan dan pengembangan program pelatihan.

\section{Perancangan Eksperimen}

Perancangan eksperimen merupakan suatu prosedur yang memungkinkan peneliti untuk mengontrol dan memastikan bahwa perubahan pada variable terikat benar-benar berhubungan dengan perubahan yang terjadi pada variable bebas dalam penelitian (Burns \& Bush, 2000). Perbandingan beberapa desain evaluasi dapat dilihat pada Tabel 4 .

Tabel 4. Perbandingan Beberapa Desain Evaluasi Pelatihan

\begin{tabular}{llccccc}
\hline \multirow{2}{*}{ Desain } & \multirow{2}{*}{ Kelompok yang diukur } & \multicolumn{5}{c}{ Pengukuran } \\
\cline { 3 - 6 } & & Sebelum & Sesudah & Biaya & Waktu & Akurasi \\
\hline Posttest-only & Peserta & Tidak & Ya & Rendah & Cepat & Rendah \\
Pretest/posttest & Peserta & Ya & Ya & Rendah & Cepat & Sedang \\
Posttest-only & Peserta dan & Tidak & Ya & Sedang & Sedang & Sedang \\
Comparison group & kelompok pembanding & & & & & \\
Pretest/posttest & Peserta & Ya & Ya & Sedang & Sedang & Tinggi \\
Comparison group & kelompok pembanding & & & & & \\
Time Series & Peserta & Ya & Ya, beberapa & Sedang & Sedang & Sedang
\end{tabular}




\begin{tabular}{llccccc} 
Time Series & Peserta & Ya & Ya, beberapa & Tinggi & Sedang & Tinggi \\
Comparison group & kelompok pembanding & & & & & \\
Solomon four-group & Peserta A & Ya & Ya & Tinggi & Lama & Tinggi \\
& Peserta B & Tidak & Ya & & & \\
& Pembanding A & Ya & Ya & & & \\
& Pembanding B & Tidak & Ya & & & \\
\hline
\end{tabular}

Sumber: Dirangkum dari Noe (2002)

Berbagai cara dapat dilakukan untuk mengevaluasi program pelatihan, namun tak ada satu pun cara yang terbaik. Desain evaluasi pelatihan sebaiknya dipilih dengan mempertimbangkan faktor biaya, tujuan pelatihan, waktu yang tersedia, dan tingkat akurasi yang diinginkan. Seringkali manajer dan supervisor tidak sepenuhnya mencurahkan waktu dan usaha untuk mengumpulkan hasil pelatihan, sehingga seringkali data sebelum dan/atau sesudah pelatihan tidak dimiliki secara lengkap (Noe, 2002).

\section{Analisis Deret Waktu (Time Series Analysis)}

Pada desain ini, hasil pelatihan dikumpulkan secara periodik selama rentang waktu tertentu, sebelum dan sesudah pelatihan. Kekuatan desain ini akan bertambah apabila peneliti menggunakan reversal dan comparison group. Reversal adalah suatu rentang waktu tertentu dimana partisipan tidak lagi menerima intervensi pelatihan. Keuntungan desain ini adalah kemampuan untuk melihat stabilitas hasil pelatihan selama rentang waktu tersebut.

\section{Penutup}

Pelatihan pada intinya bertujuan mengoptimalkan karyawan dalam menjalankan tugasnya seharihari dengan meningkatkan pengetahuan, keterampilan dan sikap kerja para karyawan melalui proses belajar.

Untuk menilai keefektifan suatu pelatihan perlu dilakukan evaluasi pelatihan. Terdapat beberapa kriteria yang dapat digunakan dalam mengevaluasi pelatihan antara lain reaksi, pembelajaran, perilaku, hasil dan ROI (Return on Investment). Menurut beberapa literatur, teknik evaluasi dengan kriteria ROI merupakan teknik yang terbaik dikarenakan teknik tersebut dinilai paling objektif dibanding empat kriteria lainnya karena dominasi unsur kuantitatif pada metode tersebut.

ROI merupakan suatu ukuran yang diperoleh oleh suatu organisasi setelah jangka waktu tertentu atas investasi suatu program pelatihan. ROI dihitung berdasarkan estimasi atau data terhadap biaya ataupun keuntungan atas program pelatihan. Tujuannya agar unit bisnis dapat mengalokasikan sumber daya yang ada secara efektif agar dapat meningkatkan kinerja dan keberhasilan suatu organisasi.

Namun, pada akhirnya tidak ada satu pun cara terbaik untuk mengevaluasi program pelatihan. Yang dapat dan penting dilakukan hanyalah berusaha mengumpulkan secara lengkap data sebelum dan/atau sesudah pelatihan agar dapat mengevaluasi program pelatihan secara akurat. Selain itu, faktor biaya; tujuan pelatihan; waktu yang tersedia; dan tingkat akurasi yang diinginkan juga perlu menjadi bahan pertimbangan dalam memilih desain evaluasi pelatihan.

\section{REFERENSI}

Kirkpatrick, Donald L., and Kirkpatrick, J. D. (2006). Evaluating Training Programs. San Francisco: Berrett-Koehler.

Burns, Alvin C. and Bush, R. F. (2000). Marketing Research. $3^{\text {rd }}$ ed. Englewood Cliff, New Jersey: Prentice-Hall.

Carr, Wendy F. "Designing an Effective Training Evaluation Process", SHRM White Paper, December 1999. 
Fitz-enz, Jac. (2000). ROI of Human Capital. New York: AMACOM, American Management Association.

Goldstein, Irwin L. (1993). Training in Organizations: Needs Assessment, Development, and Evaluation. $3^{\text {rd }}$ ed. California: Brooks/Cole Publishing Company.

Gordon, Edward E. "Training ROI: Answering the Return-on-Investment Puzzle", SHRM White Paper, August 1999.

Lilly, Frances. "Four Steps to Computing Training ROI", SHRM White Paper, February 2001.

Noe, Raymond A. (2002). Employee Training and Development. $2^{\text {nd }}$ ed. New York: McGraw-Hill.

Phillips, Jack J. (1997). Return on Investment in Training and Performance Improvement Programs. Houston: Gulf Publishing Company.

Sekaran, Uma. (2003). Research Methods for Business: A Skill-Building Approach. $4^{\text {th }}$ ed. New York: John Wiley \& Sons, Inc. 